\title{
A Research on Daily Life Activities and Geriatric Depression Levels of the Elderly in Successful Aging
}

\author{
Fahri Özsungur ${ }^{1 *}$ and Oya Hazer ${ }^{2}$ \\ ${ }^{1}$ Adana Science and Technology University, Turkey \\ ${ }^{2}$ Hacettepe University, Turkey
}

*Corresponding author: Fahri Özsungur, Adana Chamber of Commerce/Hacettepe Univ. Doctor of Philosophy in Family and Consumer Sciences, Turkey.

To Cite This Article: Fahri Özsungur, Oya Hazer. A Research on Daily Life Activities and Geriatric Depression Levels of the Elderly in Successful Aging. 2020 - 9(1). AJBSR.MS.ID.001345. DOI: 10.34297/AJBSR.2020.09.001345.

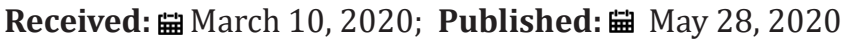

\section{Introduction}

Technologyhasgainedanimportantmomentum withinnovations in the rapid change of today's world. Data processing (1956), management information system (1965), decision support system (1976), participatory approach (1978), office automation (1980), final user calculation (1981), prototype approach (1982), strategic system planning (1984), information systems that developed as a phenomenological approach (1985) started to be applied in the production sector after 1965 [1]. Today, these technological developments have also affected communication technology. Along with interpersonal communication, communication technology has started to develop in different sectors such as healthcare, home care services, smart home systems, mobile tracking systems, personal security systems, and smartphones. The fact that this sectoral development has reached a significant level with communication technology helps daily life significantly. With distance education, individuals are provided to realize their personal development from their current location. Communication technology has made progress in many areas such as banking transactions, social media, fleet tracking systems, online shopping, video calls, online chat, health, and current information research, hotel reservation, service purchase. These rapid developments have also affected the field of gerontology. Gerontology, a multidisciplinary field with social, cultural, psychological and biological aspects of aging, has been significantly affected by changing technology and innovation. Gerontechnology, which is a multidisciplinary approach that contributes to the improvement of the quality of life of elderly people who try to adapt to their daily life and their environment, and to improve their social, mental and physical conditions, has been an important innovation in this field. Gerontechnology is an important tool in ensuring the active participation of the elderly in life, its harmony with the technological tools, the ergonomic design of technological tools and innovations in terms of the adhesion of the elderly, and providing an important factor in ensuring their physical, social and spiritual support.

However, although these developments support individuals' mobility/disabilities, they also affect depression and daily life activities. For this reason, determining the depression levels of the elderly and researching daily life activities is an important problem in the successful aging process. For this reason, the study aims to determine the geriatric depression level of the elderly, daily life activities, dependency rates related to daily life activities, instrumental daily life activities, determination of the dependency rates related to instrumental daily life activities, to make valid suggestions to families, institutions, and organizations according to the results of the research.

\section{Research Methodology}

Before the survey was applied, necessary permissions were obtained from the Senate Ethics Commission of Hacettepe University Rectorate on 06.03.2018 and from Adana Governorship Provincial Associations Directorate on 10.04.2018.

A simple random sampling method was used in the research [2]. To reach the sample easier, the sample was selected from 60 years and over-aged elderly people who were affiliated to Turkey Pensioners' Association Adana Branch in Turkey. The universe covers 32000 elderly people who are affiliated with Turkey Pensioners' Association. 
Aiming to reach 1067 participants from 32,000 elderly individuals, the sampling error was tried to be kept at 0.03. A total of 1328 participants were reached, but 416 data were excluded from the research and 912 questionnaires were evaluated and analyzed. In this case, the sampling error was 0.0325 . After these results, a sufficient number was reached to generalize the research results to the universe ( $\mathrm{n}=912$ ). In this context, survey data were evaluated and 416 surveys that did not meet the criteria were excluded from the study.

In the research, a short form of 15 questions, developed by Sheikh \& Yesavage [3] and whose validity and reliability in Turkish was performed by Durmaz et al. [4], was used to determine the level of depression of the elderly. Each statement in the scale includes two responses, "yes" and "no". The scores given to the words "yes" and "no" in the response of each question vary as " 0 " and " 1 ". A participant can get a maximum of 15 , a minimum of 0 points from this scale. As the score increases, the level of depression increases. According to the geriatric depression form, a score of 0-4 indicates that there is no depression, 5-8 points indicate mild depression, 9-11 points indicate a medium level depression, and 12-15 points indicate a severe depression level. Durmaz et al. [4] measured the Cronbach's Alpha value of the scale as .920. Cronbach's alpha value of the current research is .914 .

In the research, The Katz Activities of Daily Living (ADL) [5] and The Lawton-Brody Instrumental Activities of Daily Living (iADL) [6] scales were used to evaluate the functional capacity of the elderly.

Katz ADL was created to measure the basic level of daily life activity, such as bathing, dressing, going to the toilet, bed transfer, urinary fecal control, and eating. This scale includes 3 different responses: independent: 3, semi-dependent: 2 , fully dependent: 1 point. One participant can get at least 6 and at most 18 points. 6 points indicate that the individual is dependent on daily life activities, 7-12 points are semi-dependent and 13-18 points are independent. The increase in the scale score shows that the level of independence is increased.

The instrumental daily life activities scale, developed by Lawton and Brody [6], consists of 8 items in total and includes 3 different responses: independent: 3 , semi-dependent: 2 , fully dependent: 1 point. A participant can get a minimum of 8 and a maximum of 24 points. This scale, which consists of 8 items, measures the individual's ability to telephone, shop, prepare meals, do household chores, do laundry, get into a transport vehicle, drink her/his own medicine, manage money. The 0-8 score range shows that the participant is dependent on instrumental daily life activities, the 9-16 score range is semi-dependent, and the 17-24 score range is independent. The increase in the scale score indicates that the degree of independence is increased.

\section{Limitations of the Study}

During the data collection process, the participants were informed that the data would be kept confidential. No compelling behavior was made about participating in the participant and they were informed that they could withdraw from the survey. However, possible thought changes that may occur in the cognitive process, being influenced by the events that occur in daily life, the effects of the family, social and cultural effects, and physical and health barriers may create differences. Cognitive and environmental factors were among the limitations of the research. Due to this limitation, 416 data were determined to be inaccurate and excluded from the study.

The sample of the study was another limitation. Another limitation was that the study was conducted with individuals who were members of the Turkey Pensioners' Association, and the number of men affiliated to the association was higher than the number of women (57.5\% men; $42.5 \%$ women).

\section{Findings}

Findings regarding the demographic characteristics of the participants are shown in Table $1.57 .5 \%$ of the participants in the study were male and $42.5 \%$ were female. Individuals in the $60-65$ age range constituted $48.5 \%$ of the participants. Participants in the age group 84 and above were $1.2 \% .59 .5 \%$ of the participants stated that they were "married". It was determined that $28.4 \%$ of the elderly included in the study were high school graduates, $26.4 \%$ of them were primary school and less education level, $23.7 \%$ were bachelor's degree and above, $21.5 \%$ were secondary school graduates. $89 \%$ of the participants reported that they were retired and unemployed. $36.7 \%$ of the participants stated that they lived with their spouses, $31.5 \%$ with their family members and $29.6 \%$ of them lived alone. $69.6 \%$ of the elderly stated their perceived income as a medium level. When asked about their perceived health status in the last one month, $42.4 \%$ stated that they were good and $41 \%$ stated that they were at a moderate level (Table 1 ).

\begin{tabular}{|c|c|c|c|}
\hline \multicolumn{2}{|l|}{ Table 1: Demographic features of the participants. } & Frequency & $\%$ \\
\hline Variable & Feature & 524 & 57,5 \\
\hline \multirow{3}{*}{ Gender } & Erkek & 388 & 42,5 \\
\cline { 2 - 4 } & Kadın & 442 & 48,5 \\
\cline { 2 - 4 } Age & $60-65$ & 312 & 34,2 \\
\cline { 2 - 4 } & $66-71$ & 94 & 10,3 \\
\cline { 2 - 4 } & $72-77$ & 53 & 5,8 \\
\cline { 2 - 4 } & $78-83$ & 11 & 1,2 \\
\hline
\end{tabular}




\begin{tabular}{|c|c|c|c|}
\hline \multirow{4}{*}{ Marital Statuis } & Single & 82 & 9,0 \\
\hline & Married & 543 & 59,5 \\
\hline & Divorced & 78 & 8,6 \\
\hline & Widowed & 209 & 22,9 \\
\hline \multirow{4}{*}{ Education } & Primary school graduate and less & 241 & 26,4 \\
\hline & Secondary school graduate & 196 & 21,5 \\
\hline & High school graduate & 259 & 28,4 \\
\hline & bachelor's degree and over & 216 & 23,7 \\
\hline \multirow{4}{*}{ Working status } & Full-time (Retired) & 429 & 47,0 \\
\hline & Part-time (retired) & 89 & 9,8 \\
\hline & unemployed (retired) & 383 & 42,0 \\
\hline & Other & 11 & 1,2 \\
\hline \multirow{4}{*}{ Life Style } & Single & 270 & 29,6 \\
\hline & With spouse & 335 & 36,7 \\
\hline & With spouse/child, family members & 287 & 31,5 \\
\hline & Other & 20 & 2,2 \\
\hline Perceived & Low & 180 & 19,8 \\
\hline income & Medium & 635 & 69,6 \\
\hline status & High & 97 & 10,6 \\
\hline \multirow{5}{*}{ Perceived health in the past month } & Very good & 92 & 10,1 \\
\hline & Good & 387 & 42,4 \\
\hline & Medium & 374 & 41,0 \\
\hline & Bad & 53 & 5,8 \\
\hline & Very bad & 6 & 0,7 \\
\hline
\end{tabular}

\section{Geriatric Depression Level of Participants}

The mean score of the geriatric depression scale short form was found to be $1.83( \pm 3.32)$ (Table 2).

Table 2: Geriatric depression scale frequency, general average and standard deviation values.

\begin{tabular}{|c|c|c|c|c|c|c|}
\hline Geriatric depression & Mean & sd. & Response & Score & $\mathbf{F}$ & $\%$ \\
\hline \multirow{2}{*}{ 1. Are you basically satisfied with your life? } & \multirow{2}{*}{, 0625} & \multirow{2}{*}{,24219 } & Yes & 0 & 854 & 93,6 \\
\hline & & & No & 1 & 58 & 6,4 \\
\hline \multirow{2}{*}{$\begin{array}{l}\text { 2. Have you dropped many of your activities } \\
\text { and interests? }\end{array}$} & \multirow{2}{*}{,1316 } & \multirow{2}{*}{,33822 } & No & 0 & 792 & 86,8 \\
\hline & & & Yes & 1 & 120 & 13,2 \\
\hline \multirow{2}{*}{ 3. Do you feel that your life is empty? } & \multirow{2}{*}{,1031 } & \multirow{2}{*}{,30422 } & No & 0 & 818 & 89,7 \\
\hline & & & Yes & 1 & 94 & 10,3 \\
\hline \multirow{2}{*}{ 4. Do you often get bored? } & \multirow{2}{*}{ 1436 } & \multirow{2}{*}{ 35092 } & No & 0 & 781 & 85,6 \\
\hline & & & Yes & 1 & 131 & 14,4 \\
\hline \multirow{2}{*}{ 5. Are you in good spirits most of the time? } & \multirow{2}{*}{,1206 } & \multirow{2}{*}{,32586 } & Yes & 0 & 802 & 87,9 \\
\hline & & & No & 1 & 110 & 12,1 \\
\hline \multirow{2}{*}{$\begin{array}{l}\text { 6. Are you afraid that something bad is going } \\
\text { to happen to you? }\end{array}$} & \multirow{2}{*}{1535} & \multirow{2}{*}{,36068 } & No & 0 & 772 & 84,6 \\
\hline & & & Yes & 1 & 140 & 15,4 \\
\hline \multirow{2}{*}{ 7. Do you feel happy most of the time? } & \multirow{2}{*}{,1206 } & \multirow{2}{*}{,32586 } & Yes & 0 & 802 & 87,9 \\
\hline & & & No & 1 & 110 & 12,1 \\
\hline \multirow{2}{*}{ 8. Do you often feel helpless? } & \multirow{2}{*}{1107} & \multirow{2}{*}{,31399 } & No & 0 & 811 & 88,9 \\
\hline & & & Yes & 1 & 101 & 11,1 \\
\hline \multirow{2}{*}{$\begin{array}{l}\text { 9. Do you prefer to stay at home, rather than } \\
\text { going out and doing new things? }\end{array}$} & \multirow{2}{*}{ 1579, } & \multirow{2}{*}{ 36484 } & No & 0 & 768 & 84,2 \\
\hline & & & Yes & 1 & 144 & 15,8 \\
\hline
\end{tabular}




\begin{tabular}{|c|c|c|c|c|c|c|}
\hline \multirow{2}{*}{$\begin{array}{l}\text { 10. Do you feel you have more problems with } \\
\text { memory than most? }\end{array}$} & \multirow{2}{*}{,1206 } & \multirow{2}{*}{,32586 } & No & 0 & 802 & 87,9 \\
\hline & & & Yes & 1 & 110 & 12,1 \\
\hline \multirow{2}{*}{$\begin{array}{l}\text { 11. Do you think it is wonderful to be alive } \\
\text { now? }\end{array}$} & \multirow{2}{*}{,1075 } & \multirow{2}{*}{,30986 } & Yes & 0 & 814 & 89,3 \\
\hline & & & No & 1 & 98 & 10,7 \\
\hline \multirow{2}{*}{$\begin{array}{l}\text { 12. Do you feel pretty worthless the way you } \\
\text { are now? }\end{array}$} & \multirow{2}{*}{, 1217} & \multirow{2}{*}{,32713 } & No & 0 & 801 & 87,8 \\
\hline & & & Yes & 1 & 111 & 12,2 \\
\hline \multirow{2}{*}{ 13. Do you feel full of energy? } & \multirow{2}{*}{, 1327} & \multirow{2}{*}{,33941 } & Yes & 0 & 791 & 86,7 \\
\hline & & & No & 1 & 121 & 13,3 \\
\hline \multirow{2}{*}{ 14. Do you feel that your situation is hopeless? } & \multirow{2}{*}{,1086 } & \multirow{2}{*}{,31125 } & No & 0 & 813 & 89,1 \\
\hline & & & Yes & 1 & 99 & 10,9 \\
\hline \multirow{2}{*}{$\begin{array}{l}\text { 15. Do you think that most people are better } \\
\text { off than you are? }\end{array}$} & \multirow{2}{*}{ 1371 } & \multirow{2}{*}{,34410 } & No & 0 & 786 & 86,2 \\
\hline & & & Yes & 1 & 126 & 13,8 \\
\hline \multirow{2}{*}{$\begin{array}{l}\text { General Average of Geriatric Depression Scale } \\
\text { (min. 0- max. 15) }\end{array}$} & \multirow{2}{*}{1,83} & \multirow{2}{*}{3,32} & No & $0-1$ & 8441 & 61,70 \\
\hline & & & Yes & $0-1$ & 5239 & 38,30 \\
\hline
\end{tabular}

F: frequency, sd. Standard deviation

It was determined that $82.2 \%$ of the participants were not depressed, $10.4 \%$ were in "mild depression", 5.8\% were in "moderate depression" and $1.5 \%$ were in "severe depression" (Table 3).

\begin{tabular}{|c|c|c|}
\hline \multicolumn{3}{|c|}{ Table 3: Distribution of Participants by Depression Levels. } \\
\hline Depression Levels & F & \% \\
\hline No Depression (0-4 score range) & 750 & 82,2 \\
\hline Mild Depression (5-8 score range) & 95 & 10,4 \\
\hline Moderate Depression (9-11 score range) & 53 & 5,8 \\
\hline Severe Depression (12-15 score range) & 14 & 1,5 \\
\hline
\end{tabular}

\section{Daily Life Activities of the Participants}

The average daily life activities (ADL) score of the participants was measured as 16.88 (min.6-max.36) and standard deviation 3.30. The participants' daily life activity with the highest average was "go to the toilet" (avg. 2.84; \pm 1.12 ), and the lowest average was "to be able to take a bath" (avg. 2.79; \pm , 54), "dressing status" (avg. $2.79 ; \pm, 51)$.

\begin{tabular}{|c|c|c|}
\hline \multicolumn{3}{|c|}{$\begin{array}{l}\text { Table 4: General Average and Standard Deviations of the Item and } \\
\text { Scale Related to the Level of Daily Life Activities of the Participants. }\end{array}$} \\
\hline Daily Life Activities & Mean & Sd. \\
\hline Bathing & 2,79 &, 54 \\
\hline Dressing & 2,79 &, 51 \\
\hline Toileting & 2,84 & 1,12 \\
\hline $\begin{array}{c}\text { Movement status (Transfer, a bed to the } \\
\text { room, etc.) }\end{array}$ & 2,82 & 1,12 \\
\hline $\begin{array}{c}\text { Continence status (incontinence) } \\
\text { Feeding }\end{array}$ & 2,82 & 1,12 \\
\hline $\begin{array}{c}\text { General Average for ADL Scale (min. 6- max. } \\
\text { 36) }\end{array}$ & 2,82 & 16,88 \\
\hline
\end{tabular}

In Table 4, the dependency rates of the elderly who were included in the study were given according to ADL. Accordingly, it was determined that $88.6 \%$ of the participants were "independent",
8.7\% were "semi-dependent" and $2.7 \%$ were "fully dependent" (Table 5).

\begin{tabular}{|c|c|c|}
\hline \multicolumn{3}{|c|}{ Table 5: Dependency Rates of Participants on Daily Life Activities. } \\
\hline Daily Life Activities Level & F & $\mathbf{\%}$ \\
\hline Independent & 808 & 88,6 \\
\hline Semi Dependent & 79 & 8,7 \\
\hline Fully Dependent & 25 & 2,7 \\
\hline
\end{tabular}

\section{Instrumental Daily Life Activities of the Participants}

The instrumental daily living activities (iADL) score average of the participants was 21.51 (min.6-max.48) and the standard deviation was 5.01. The instrumental daily life activity of the participants with the highest average was "the ability to get their own medicine" (avg. 2.79; \pm 1.52 ), and the lowest average was the "housekeeping" (avg. 2.56; \pm , 66).

Dependency ratios of the elderly included in the study are given in Table 6. Accordingly, $85.1 \%$ of the participants were detected to be "independent", the level of instrumental daily life activities was "independent", $11.7 \%$ were "semi-dependent" and 3.2\% were "fully dependent" (Table 7).

Table 6: General Average and Standard Deviations of the Item and the Scale Related to the Level of Instrumental Daily Living Activities of the Participants.

\begin{tabular}{|c|c|c|}
\hline Instrumental Daily Living Activities & Mean & Sd. \\
\hline Ability to Use Telephone & 2,76 &, 53 \\
\hline Shopping & 2,64 &, 62 \\
\hline Food Preparation & 2,68 & 1,53 \\
\hline Housekeeping & 2,56 &, 66 \\
\hline Laundry & 2,65 & 1,55 \\
\hline Mode of Transportation & 2,66 &, 62 \\
\hline Responsibility for Own Medications & 2,79 & 1,52 \\
\hline Ability to Handle Finances & 2,77 & 1,15 \\
\hline $\begin{array}{c}\text { General Average of iADL Scale (min. 6- max. } \\
\text { 48) }\end{array}$ & 21,51 & 5,01 \\
\hline
\end{tabular}


Table 7: Dependence Rates of Participants Regarding Instrumental Daily Living Activities.

\begin{tabular}{|c|c|c|}
\hline Instrumental Daily Life Activities Level & F & \% \\
\hline Independent & 776 & 85,1 \\
\hline Semi Dependent & 107 & 11,7 \\
\hline Fully Dependent & 29 & 3,2 \\
\hline
\end{tabular}

\section{Discussion and Conclusion}

When the general results of the elderly individuals included in the research were examined, it was determined that more than half of the elderly individuals were male (57.5\% male; $42.5 \%$ female), nearly half of the elderly were between the ages of $60-65$ (48.5\%), a little over half of the elderly were married (59.5\%), 8.6\% were divorced, $9 \%$ were single, considering the education levels of the elderly included in the study, the number of high school graduates was high $(28.4 \%)$, followed by the primary school or less education with $26.4 \%$ and secondary school graduates with the lowest level with $21.5 \%$. On the other hand, findings showed that $47 \%$ of the elderly were retired full-time employees and $42 \%$ of the participants were retired and unemployed. When the lifestyle of the elderly was analyzed, it was determined that $36.7 \%$ of them lived with their spouses, followed by those living with their spouse/child/family members with $31.5 \%$. It was determined that more than half of the elderly (69.6\%) perceived their income levels at a medium level, while $19.8 \%$ of the elderly perceived them at a low level, and those who perceived at a high level were the lowest stage (10.6\%).

It was found that those who perceived the health status of the elderly individuals who participated in the study in the last month were at the forefront $(42.4 \%)$, followed by those who perceived it as moderate at $41 \%$ and those who perceived it as very bad at the lowest level of $0.7 \%$. When the geriatric depression levels of the elderly were examined, it was determined that $82.2 \%$ of them were not depressed. It was determined that $88.6 \%$ of the elderly individuals were "independent", 8.7\% were "semi-dependent" and $2.7 \%$ were "fully dependent". The highest average daily living activity was "the ability of toilet" (avg. 2.84; \pm 1.12 ), and the lowest average was "the ability of bathing" (avg. 2.79; \pm ,54) and "dressing" (2.79; \pm , 51). It was determined that the instrumental daily life activities of $85.1 \%$ of the elderly were "independent", $11.7 \%$ were "semi-dependent" and $3.2 \%$ were "fully dependent". The highest average instrumental daily life activity was found to be "Responsibility for Own Medications" (average $2.79 ; \pm 1.52$ ) and the lowest mean to be "housekeeping" (average 2.56; \pm , 66).

Geriatric depression has been investigated in the literature regarding cognitive decline, dementia and physical diseases [716]. Studies have shown that the level of geriatric depression is associated with increasing age [10-16]. However, the current study reveals that the level of depression does not depend on increasing age, but is related to the high level of daily living activities.
According to the results, it was determined that the individuals who were successfully aging were not depressed and they performed their instrumental and daily life activities independently. These results reveal the importance of the successful aging of the elderly in the context of depression and daily life activities. For this reason, it is recommended that policymakers take remedial measures to carry out psychological factors and daily activities independently. On the other hand, individuals should be trained on these issues. For future studies, it is recommended to increase the researches in this direction on the elderly with different demographic characteristics.

\section{References}

1. Er MC (1990) The History of the Development of Information Technology and its Organizational and Societal Impact. Journal of Information and Optimization Sciences 11(1): 113-143.

2. Sencer M (1989) Toplumbilimlerinde yöntem. Beta Basım, İstanbul.

3. Yesavage Sheikh JI, Yesavage JA (1986) Geriatric Depression Scale (GDS): Recent Evidence and Development of a Shorter Version. Clinical Gerontologist: The Journal of Aging and Mental Health 5(1-2): 165-173.

4. Durmaz B, Soysal P, Ellidokuz H, Işık AT (2018) Validity and reliability of geriatric depression scale-15 (short form) in Turkish older adults. North Clin Istanb 5(3): 216-220.

5. Katz S, Downs TD, Cash HR, Grotz RC (1970) Progress in Development of the Index of ADL. Gerontologist 10(1): 20-30.

6. Lawton MP, Brody EM (1969) Assessment of Older People: Selfmaintaining and Instrumental Activities of Daily Living. Gerontologist 9(3): 179-186.

7. Brink TL, Yesavage JA, Lum O, Heersema PH, Adey M, et al. (1982) Screening tests for geriatric depression. Clinical gerontologist 1(1): $37-$ 43.

8. Alexopoulos GS, Vrontou C, Kakuma T, Meyers BS, Young RC, et al. (1996) Disability in geriatric depression. The American journal of psychiatry 153(7): 877-885

9. Lockwood KA, Alexopoulos GS, Wilfred G van Gorp (2002) Executive dysfunction in geriatric depression. American Journal of Psychiatry 159(7): 1119-1126.

10. Steffens DC, Byrum CE, McQuoid DR, Greenberg DL, Payne ME, et al. (2000) Hippocampal volume in geriatric depression. Biological psychiatry 48(4): 301-309.

11. Alexopoulos GS, Kiosses DN, Heo M, Murphy CF, Shanmugham B, et al. (2005) Executive dysfunction and the course of geriatric depression. Biological psychiatry 58(3): 204-210.

12. Scogin F, McElreath L (1994) Efficacy of psychosocial treatments for geriatric depression: a quantitative review. Journal of consulting and clinical psychology 62(1): 69-74.

13. Lesher EL, Berryhill JS (1994). Validation of the geriatric depression scale-short form among inpatients. Journal of clinical psychology 50(2): 256-260.

14. Alexopoulos GS, Meyers BS, Young RC, Mattis S, Kakuma T (1993) The course of geriatric depression with" reversible dementia": a controlled study. American Journal of Psychiatry 150(11): 1693-1699.

15. Merkin AG, Medvedev ON, Sachdev PS, Tippett L, Krishnamurthi R, et al. (2020) New avenue for the geriatric depression scale: Rasch transformation enhances reliability of assessment. Journal of Affective Disorders 264: 7-14.

16. Naveen KHS, Goel AD, Dwivedi S, Hassan MA (2020) Adding life to years: Role of gender and social and family engagement in geriatric depression in rural areas of Northern India. Journal of Family Medicine and Primary Care 9(2): 721-728. 